\title{
Torsion of the Testicular Appendages in Adult Acute Scrotum
}

\author{
Seiichi Saito \\ Art Park Urology Hospital \& Clinic, Sapporo, Japan \\ Email address: \\ apusss@mb.infosnow.ne.jp
}

\section{To cite this article:}

Seiichi Saito. Torsion of the Testicular Appendages in Adult Acute Scrotum. International Journal of Clinical Urology.

Vol. 3, No. 2, 2019, pp. 40-45. doi: 10.11648/j.ijcu.20190302.13

Received: August 28, 2019; Accepted: October 15, 2019; Published: October 26, 2019

\begin{abstract}
Adult patients with acute scrotum sometimes tend to be treated for epididymitis without undergoing ultrasonographic examination, although precise ultrasonography reveals that there are some patients with torsion of the testicular appendages. In this report, I investigate the incidence of patients with torsion of the testicular appendages among patients with adult acute scrotum, who mainly used to be treated for epididymitis. In the last 5 years, 46 patients $(23 \sim 62$, average age 43.5 years) with scrotal pain and swelling visited our clinic for diagnosis and treatment. On an outpatient basis, their symptoms were evaluated, and blood tests, urinalysis, and grey scale and color Doppler ultrasonography with a $5-12 \mathrm{MHz}$ linear scan were performed. Five (10.9\%) of the 46 patients were diagnosed as having torsion of the testicular appendages. Although none of them had a high fever, 4 of the $5(80 \%)$ had nausea and abdominal pain. Leukocytosis and pyuria were not found in any case. Typical ultrasound appearances were reactive hydrocele and a hyperechoic swollen mass or enlarged hyperechoic, spherical mass of the appendage. On color Doppler ultrasonography, there was no blood flow within the torsed appendage testis, and an increase in periappendiceal blood flow was seen in all of the cases. They were treated conservatively with anti-inflammatory agents and cooling, and their symptoms disappeared within 2 weeks. It is suggested that as many as $10.9 \%$ of adult patients with scrotal pain and swelling may suffer from torsion of the testicular appendages. We should conduct ultrasonography for adult patients with acute scrotum.
\end{abstract}

Keywords: Torsion of the Testicular Appendages, Appendix Testis, Appendix Epididymitis, Acute Scrotum

\section{Introduction}

Torsion of the testicular appendages is one of the most frequent causes of acute scrotum in prepubertal boys [1-6]. The appendix testis, sometimes called hydatid of Morgani, is a Mullerian duct remnant and is present in 76 to $83 \%$ of testis [5, 6], whereas epididymal appendages are vestigial remnants of the Wolffian duct system and are present in 22 to $28 \%$ of testis $[5,6]$. The appendix testis is particularly susceptible to torsion because it is often pedunculated. It is homologous to the fimbriated end of the Fallopian tube in the female [5]. It accounts for $95 \%$ of cases of appendage torsion $[3,4]$. The etiology of appendiceal torsion is not known; however, the clinical scenario may mimic that of testicular torsion. The onset of pain usually occurs gradually over a day or two, although it can be acute and severe. Torsion of the testicular appendages is benign condition and necrotic tissue is reabsorbed without any sequelae in almost all cases.
Although most adult patients with scrotal pain and swelling such as acute scrotum are treated for epididymitis because of epididymal swelling and tenderness, we sometimes encounter patients with nausea and abdominal pain without pyuria. In such cases, precise ultrasonography reveals there are some patients with torsion of the testicular appendages.

However, to the best of my knowledge, no study of this phenomenon has been performed in adult cases. In this report, I reviewed our cases with adult acute scrotum that, without ultrasonographic examination, used to be diagnosed as epididymitis.

\section{Materials and Methods}

I retrospectively reviewed the medical records of 46 consecutive patients who came to our clinic for help due to acute scrotum in the last 5 years (January $2014 \sim$ December 2019). In all cases, clinical findings (age, location, onset, 
duration of pain, fever, nausea/vomiting, abdominal pain), physical examination findings (erythema, testicular swelling, scrotal edema, testicular tenderness, UTI symptoms, blue dott sign), laboratory data (leucocyte count, CRP, urinalysis) and grey scale and color Doppler ultrasonography findings were collected. The ultrasonography was performed by single urologist to evaluate the acute scrotum in the daily clinical setting.

The patients' ages ranged from 23 to 62 years (mean 45.2 years). The diagnosis of the testicular appendages was based on pertinent sonographic findings with clinical improvement after conservative treatment $(n=5)$. All sonographic examinations were performed with a 5-12 MHz linear array transducer (BK Medical ApS, Pro Focus 2202, Type 8811, Denmark). At the same time color Doppler sonography and power Doppler sonography were performed with optimized color Doppler parameters. The power level, threshold, persistence, and wall filter were individually adjusted to maximize the detection of blood flow through the field of view.

Clinical presentation and examination results, including physical examination, laboratory data, and the findings of grey scale and color Doppler ultrasonography (5-12 MHz linear scan) were analyzed.

Categorical data between groups were compared using $\mathrm{x}^{2}$ test or Fisher's exact test while continuous distributed data were compared using either Mann-Whitney U test or analysis of variance. A p value of less than 0.005 was considered to be statistically significant.

\section{Results}

A total of 46 consecutive patients were included in this study and divided into 2 groups according to their final diagnosis. Five patients $(10.9 \%)$ had torsion of the testicular appendages and $41(89.1 \%)$ had epididymitis. All patients were diagnosed according to ultrasonography. The characteristics of the two groups are presented in Table 1. Five $(10.9 \%)$ of the 46 patients were diagnosed as having torsion of the testicular appendages. The mean age of patients with torsion of the testicular appendages and epididymitis were almost the same. Acute onset of testicular pain presented more frequently in patients with torsion of the testicular appendages $(20 \%)$ than in patients with epididymitis $(9.8 \%)$. The duration of pain in both groups was almost the same. Although none of them had a high fever, 4 of the $5(80 \%)$ had nausea and abdominal pain. Leukocytosis and pyuria were not found in any case, as shown in Table 2. Typical ultrasound appearances at onset were reactive hydrocele and a hyperechoic swollen mass or enlarged hyperechoic, spherical mass of the appendage as shown in Figure 1. And the size of enlarged swollen mass was decreasing gradually as shown in Figures 2 and 3 .

In terms of the shape of the testicular appendages at onset, a spherical shape was seen in all of 5 cases of torsed appendix testis. On color Doppler sonography, there was no blood flow within the torsed testicular appendage (Figure 4). An increase in periappendiceal blood flow was seen in all of the cases of torsed appendix testis, but this increase was also seen in the case of epididymitis as shown in table 3 . Therefore there was no significant difference between the torsion of the testicular appendage group and the epididymitis group on color Doppler ultrasonography. They were treated conservatively with anti-inflammatory agents and cooling, and their symptoms disappeared within 2 weeks.

Table 1. Characteristics of different acute scrotum patient groups.

\begin{tabular}{llll}
\hline & \multirow{2}{*}{ Torsion of the testicular appendages $(\mathbf{n}=\mathbf{5})$} & Epididymitis & \\
\cline { 3 - 4 } & $\mathbf{( n = 4 1 )}$ & $\boldsymbol{p}$ & \\
\hline Ages (yr) & $23 \sim 62(43.5)$ & $28 \sim 60(48.3)$ & N.S. \\
Location Right & $2(40 \%)$ & $20(48.8 \%)$ & N.S. \\
Left & $3(60 \%)$ & $21(51.2 \%)$ & N.S. \\
Acute onset of pain & $1(20 \%)$ & $4(9.8 \%)$ & N.S. \\
Duration of pain $(\mathrm{hr})$ & 20.5 & 25.5 & N.S. \\
\hline
\end{tabular}

N.S.: not significant

Table 2. Clinical findings and laboratory data of different acute scrotum patient groups.

\begin{tabular}{|c|c|c|c|}
\hline & \multirow{2}{*}{ Torsion of the testicular appendages $(n=5)$} & \multicolumn{2}{|c|}{ Epididymitis } \\
\hline & & $(n=41)$ & $p$ \\
\hline Fever & $0(0 \%)$ & $22(53.6 \%)$ & 0.005 \\
\hline Nausea/vomiting & $4(80 \%)$ & $1(2.4 \%)$ & 0.005 \\
\hline Abdominal pain & $4(80 \%)$ & $10(24.4 \%)$ & N.S. \\
\hline Erythema & $3(60 \%)$ & $30(73.2 \%)$ & N.S. \\
\hline Testicular swelling & $1(20 \%)$ & $25(61.0 \%)$ & 0.005 \\
\hline Scrotal edema & $0(0 \%)$ & $15(36.6 \%)$ & 0.005 \\
\hline UTI symptoms & $0(0 \%)$ & $10(24.4 \%)$ & 0.005 \\
\hline Blue dot sign & $2(40 \%)$ & $0(0 \%)$ & 0.005 \\
\hline \multicolumn{4}{|l|}{ Laboratory data } \\
\hline Leucocytosis & $0(0 \%)$ & $23(56.1 \%)$ & 0.005 \\
\hline CRP & $0(0 \%)$ & $23(56.1 \%)$ & 0.005 \\
\hline Pyuria & $0(0 \%)$ & $38(92.7 \%)$ & 0.001 \\
\hline
\end{tabular}


Table 3. Results of grey scale and color Doppler sonographic features of the testicular appendages and epididymitis.

\begin{tabular}{|c|c|c|c|}
\hline & \multirow{2}{*}{ Torsion of the testicular appendages $(n=5)$} & \multicolumn{2}{|l|}{ Epididymitis } \\
\hline & & $(n=41)$ & $p$ \\
\hline Average size $(\mathrm{mm})$ & $10.6 \mathrm{~mm}$ & $4.8 \mathrm{~mm}$ & 0.005 \\
\hline Reactive hydrocele & $5(100 \%)$ & $31(75.6 \%)$ & N.S. \\
\hline \multicolumn{4}{|l|}{ Shape } \\
\hline Spherical & $5(100 \%)$ & 0 & 0.001 \\
\hline Ovoid & 0 & $26(73.2 \%)$ & 0.001 \\
\hline Pedunculated & 0 & $15(26.8 \%)$ & 0.005 \\
\hline \multicolumn{4}{|l|}{ Echogenicity } \\
\hline Hyperechoic & $5(100 \%)$ & $15(26.8 \%)$ & 0.005 \\
\hline Isoechoic & 0 & $26(73.2 \%)$ & 0.005 \\
\hline \multicolumn{4}{|c|}{ Blood flow within appendix } \\
\hline Present & 0 & $10(24.4 \%)$ & 0.005 \\
\hline Absent & $5(100 \%)$ & $10(75.6 \%)$ & N.S. \\
\hline \multicolumn{4}{|c|}{ Increased periappendiceal blood flow } \\
\hline Present & $5(100 \%)$ & $41(100 \%)$ & N.S. \\
\hline Absent & 0 & 0 & N.S. \\
\hline
\end{tabular}

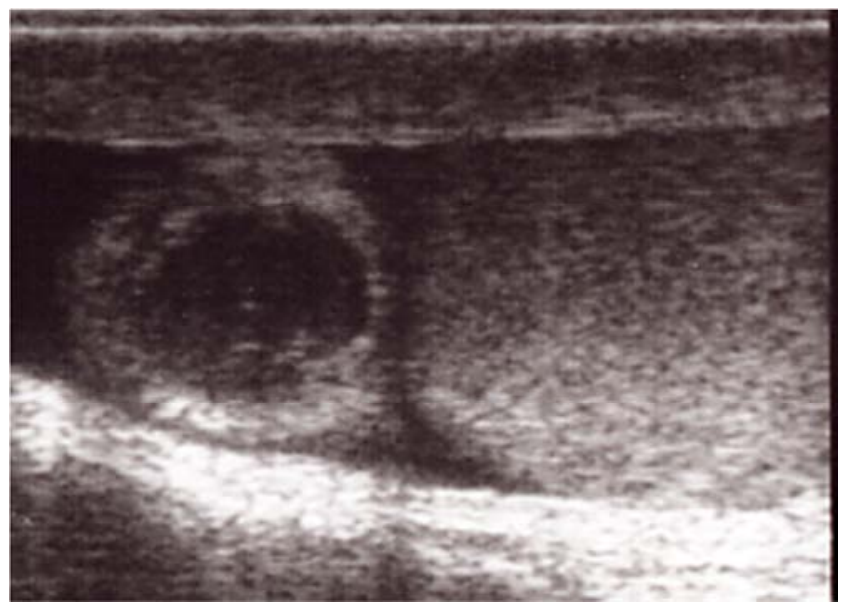

Figure 1. Longitudinal grey scale sonogram showing an enlarged hyperechoic, spherical appendix testis at onset.

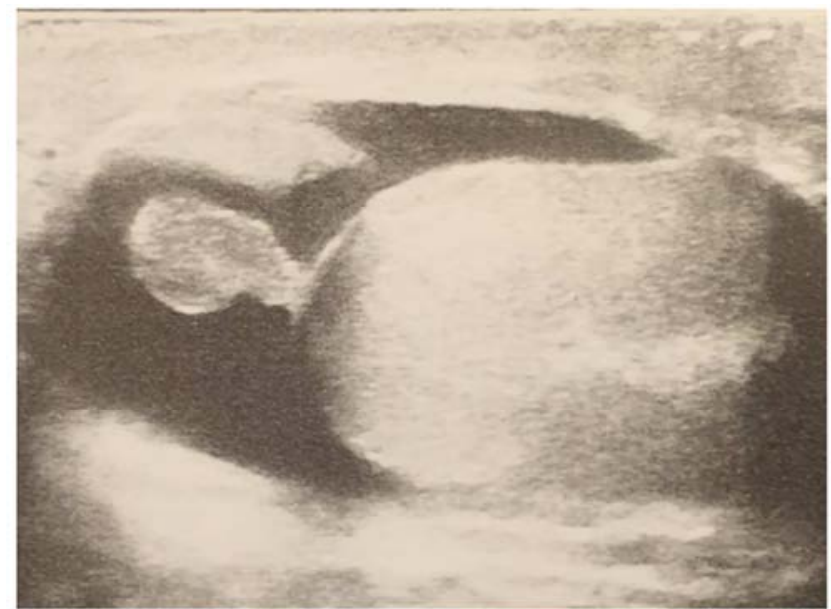

Figure 2. Reactive hydrocele and a hyperechoic swelling mass of the appendage after 5 days treatment.

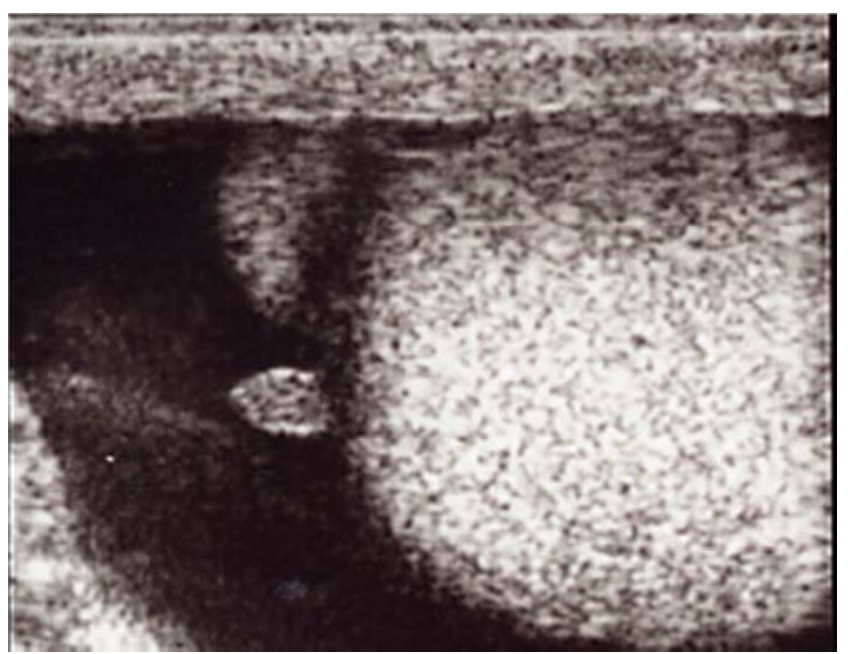

Figure 3. Reactive hydrocele and a hyperechoic small mass of the appendage after 10 days treatment.

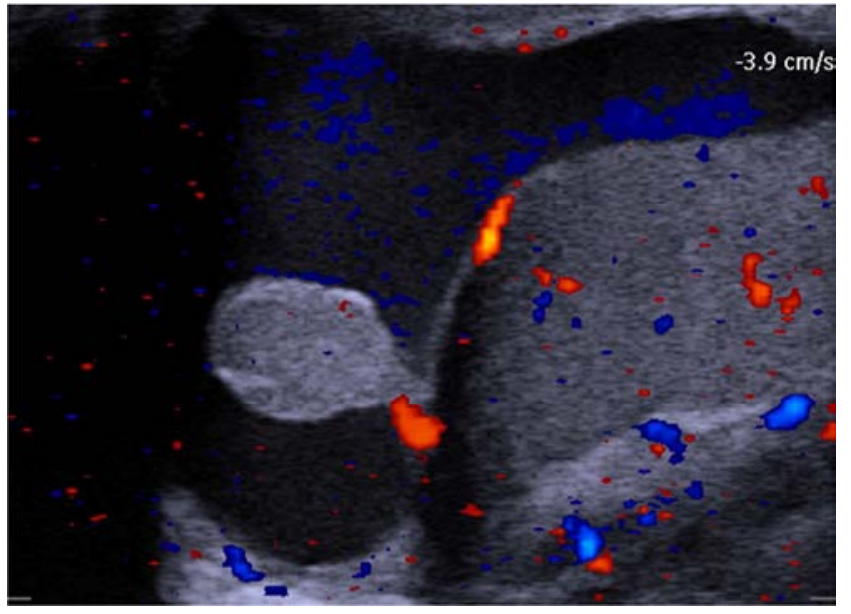

Figure 4. Longitudinal color Doppler sonogram of a torsed appendix testis showing reactive hydrocele and an enlarged ovoid appendix testis after 5 days treatment. The echogenicity of the appendix testis is hyperechoic to the testis. It also shows increased periappendiceal blood flow, but there is no blood flow within the appendix testis. 


\section{Discussion}

Acute testicular pain or swelling, often referred to as "acute scrotum", can have a number of cases. In the past, immediate surgical exploration was the standard approach when torsion was suspected. However, studies have shown that only $16-42 \%$ of boys with acute scrotum have testicular torsion [7-9], and negative findings of testicular torsion at surgery were reported in $62-88 \%$ of cases [1,9-11]. A "blue dot sign " may also be present as a para-testicular nodule noted on the superior aspect of the testicle; this can be identified by stretching the scrotal skin overlying the superior pole of the testicle and is representative of an ischemic testicular appendage. While worth knowing, the "blue dot sign" is only present in about $21 \%$ (0 to $52 \%$ ) of all torsed testicular appendages and a false positive "blue dot sign" has been reported in the literature in a patient with testicular torsion [12]. In an effort to improve diagnostic accuracy and avoid needless surgery, precise grey scale and color Doppler ultrasonography have been performed to evaluate the cause of acute scrotum [13]. In young ages, testicular torsion, epididymitis, and torsion of the testicular appendages are the most common etiologies of acute scrotum [8, 14-16]. The peak age of occurrence is 7 to 12 years, although it can occur at any age. More than $50 \%$ of boys presenting with acute scrotal pain will have torsion of a testicular appendages. In one study of 238 boys aged 19years and younger who presented to children's hospital with acute scrotal pain, $46 \%$ were ultimately found to have torsion of the appendix testis while $35 \%$ had epididymitis and only $16 \%$ demonstrated testicular torsion [17]. Although most cases of acute scrotum in adult used to be diagnosed and treated for epididymitis because of epididymal swelling and tenderness, we sometimes encounter patients with nausea and abdominal pain without pyuria. In such cases, precise examinations with grey scale and color Doppler ultrasonography reveal there are some patients with torsion of the testicular appendages. In our series, $10.9 \%$ of the patients were diagnosed as having torsion of the testicular appendages. Although none of them had a high fever, $80 \%$ had nausea and abdominal pain. Leukocytosis and pyuria were not found in patients with torsion of the testicular appendages. Thus, we should think about torsion of the testicular appendages when we see adult patients with nausea and abdominal pain without fever and pyuria. Four testicular appendages have been identified: the appendix testis (a remnant of the paramesonephric duct), the appendix epididymis (a remnant of the mesonephric duct), the paradidymis (organ of Giraldes) and the vas aberrans (organ of Haller). The appendix testis is present in $92 \%$ of all testes and is usually located at the superior testicular pole in the groove between the testicle and the epididymis $[3,4]$. The most common testicular appendages susceptible to torsion is the appendix testis, which is a vestigial remnant of the mesonephric and Mullerian duct systems. It is located at the upper pole of the testis in the groove between the testis and the head of the epididymis [18-24]. Histologically, the normal appendix testis is formed of loose gelatinous vascular connective tissue stroma covered by Mullerian-type cuboidal to columnar epithelium. It may be responsible for controlling the amount of serous fluid in the space of the tunica vaginalis $[25,26]$. Although a characteristic blue dot sign on the skin of the scrotum may appear and palpation of a tender mass near the upper pole of the testis may be possible, once edema occurs, it becomes impossible to use palpation and the appearance for diagnosis. Therefore, we need precise ultrasonography for differential diagnosis. In ultrasonography, the normal appendix testis is oval or pedunculated shape and is around $5 \mathrm{~mm}$ in length [18-25]. The ultrasonographic findings of torsion of the testicular appendages are: 1) increased size with an increase or decrease in echo texture, 2) reactive hydrocele, and 3) scrotal wall thickening [1, 8, 9]. However, the size and echogenicity of the normal and torsed appendix overlap on ultrasonography. Yang et al. [27] reported that they observed several differences between torsed and normal testicular appendages on gray scale and color Doppler ultrasonography, such as the size and shape of the appendix testis and the degree of periappendiceal blood flow. In terms of size, the torsed appendix testis is larger than the normal appendix testis. In their study, the size of the torsed appendix testis ranged from 5 to $10 \mathrm{~mm}$ (mean, $7 \mathrm{~mm}$ ), and the size of the normal appendix testis ranged from 1.6 to $4.3 \mathrm{~mm}$ (mean, $3.1 \mathrm{~mm}$ ). Therefore, in their study, the cutoff point was $5 \mathrm{~mm}$ or larger for the size of the appendix testis as a sonographic criterion suggesting the presence of torsion. These results are in accordance with those of another study [20], which reported that the size of the torsed appendix testis ranged from 5 to $16 \mathrm{~mm}$. However Strauss's study [20] reported that the size of the normal appendix testis ranged from 1 to $7 \mathrm{~mm}$. The differences in results between Strauss's study and Yang's study may be explained by the difference in age groups that were used in the studies. In Yang's study [27], the mean age of the control group was 9 years. In contrast, the mean age in Strauss's study [20] was 43 years. The normal appendix testis in children may be smaller than that in adults. Therefore, the size of the appendix testis may be helpful in the diagnosis of torsion of the appendix testis in which, if the appendix testis is $7 \mathrm{~mm}$ or larger, it is indicative of a torsed appendix testis in adults. Although the size of the appendix testis depends on the body size of the patient and it is very difficult to distinguish the torsion from the size, we concluded that the cutoff point was $7 \mathrm{~mm}$ or larger for the size of the appendix testis as a sonographic criterion suggesting the presence of torsion. An increase in periappendiceal blood flow was seen in several cases, but this was not positive for every case of torsion of the appendix. This increase in periappendiceal blood flow was also seen in the case of epididymitis. Nor was there a significant difference in echogenicity between the torsed and normal appendix testes. Therefore, the shape of the appendix testis and reactive hydrocele can be useful indicators for diagnosing a torsed appendix testis. Most of the torsed appendix testes were spherical. Although the normal appendix testis is isoechoic to the head of the epididymis, a torsed appendix testis usually appears hyperechoic on ultrasonography. However, the echogenicity of the torsed 
appendix testis is not useful in differentiating between torsed and normal appendix testes.

Rakha E. et al [28] reported the histology of the testicular appendages. They found a positive correlation between the degree of acute inflammatory cell infiltration and the length of duration of symptoms, and the presence of a clinical evidence of torsion of the testicular appendages. They did not, however, find any association between the pattern or degree of acute inflammatory cell infiltrates and various clinicopathological features that might suggest pyogenic infection such as high temperature, marked scrotal redness and swelling, the development of postoperative complications, evidence of urinary infection or the presence of associated epididymo-orchitis. Moreover, as the presence of considerable acute inflammatory infiltrates in some patients may be secondary to local infection, they used special stains to check for the presence of organisms that are commonly associated with acute inflammatory cell infiltrates. No bacteria or fungi were identified, however. They concluded that, despite its histological appearance, the acute inflammation in these cases was not attributable to infection. Although they could not find the cause of this heavy acute inflammatory cell infiltrate, they are led by exclusion to believe that it was a response to tissue damage owing to the torsion. These results also showed that the pattern or degree of acute inflammatory cell infiltrates in these tortuous appendices had no clinical importance. They also noted that marked lymphatic dilation (without hemorrhage, necrosis or inflammatory cell infiltration) might be the first histological finding in cases of scrotal pain that are genuinely due to early torsion of the testicular appendix. Thus, the presence of lymphatic dilation with or without stromal edema can be used as a marker to assess the presence of early torsion of the appendices testis. Their data show that the presence of a heavy acute inflammatory infiltrate in cases of torsion appendix testis is merely a reflection of the duration of the torsion and does not indicate the presence of any other pathological process.

In this report, I found that, although torsion of the testicular appendages is reported to occur typically in prepubertal boys, it was not uncommon in adult males. It is suggested that as many as $10.9 \%$ of adult patients with scrotal pain and swelling may suffer from torsion of the testicular appendages. Therefore we should conduct ultrasonography for adult patients with acute scrotum.

These data were presented at the $99^{\text {th }}$ American Urological Association held in SanAntonio, USA.

\section{Conclusions}

Although the sample size was limited, based on the findings of this study the following tentative conclusions can be drawn. As many as $10.9 \%$ of adult patients with scrotal pain and swelling may suffer from torsion of the testicular appendages. Although none of them had a high fever, some of them had nausea and abdominal pain. Typical ultrasound appearances are reactive hydrocele and a hyperechoic swollen mass or enlarged hyperechoic, spherical mass of the appendage. On color Doppler ultrasonography, there is no blood flow within the torsed appendix testis, and an increase in periappendiceal blood flow can be observed. Such cases can be treated conservatively with anti-inflammatory agents and cooling and the symptoms will disappear within 2 weeks.

\section{References}

[1] McAndrew HF, Pemberton R, Kikiras CS (2002). The incidence and investigation of acute scrotal problems in children. Pediatric Surgery Internationalis 1, 435-437.

[2] Mushtaq I, Fung M, Glasson MJ (2003). Retrospective review of pediatric patients with acute scrotum. ANZ Journal of Surgery $73,55-59$.

[3] Skoglund RW, McRoberts JW, Ragde H (1970). Torsion of testicular appendages: presentation of 43 new cases and a collective review. Journal of Urology 104, 598-600.

[4] Ruiz Montes AM, Jimenez AC, Nunez NR (1994). The clinical characteristics of patients with torsion of the testicular and epididymal appendages. Cirgia Pediatrica 7, 140-142.

[5] Pomajizi AJ, Leslie SW (2019). Appendix testis torsion. Stat Pearls [Internet]. Treasure Island (FL): Stat Pearls Publishing.

[6] Park SJ, Kim HL, Yi BH. (2011). Sonography of intrascrotal appendage torsion: varying echogenicity of the torsed appendage according to time from onset. Journal of Ultraound of Medicine. 30 (10), 1391-1396.

[7] Lewis AG, Bukowski TP, Jarvis PD (1995). Evaluation of acute scrotum in the emergency department. Journal of Pediatric Surgery 30:, 272-282.

[8] Mufti RA, Ogedegbe AK, Lafferty K (1995). The use of Doppler ultrasound in the clinical management of acute testicular pain. British Journal of Urology 76, 625-627.

[9] Watkin NA, Reiger NA, Moisey CU (1996). Is the conservative management of the acute scrotum justified on clinical grounds. British Journal of Urology 78, 623-627.

[10] Kass EJ, Lundak B (1997). The acute scrotum. Pediatric Urology 44, 1251-1266.

[11] Karmazyn B, Sternberg R, Kornreich L (2005). Clinical and sonographic criteria of acute scrotum in children. Pediatric Radiology 35, 302-310.

[12] Kim JS, Shin YS, Park JK. (2018). Clinical features of acute scrotum in children and adolescence: Based on 17 years experiences in primary care clinic. American Journal of Emergent Medicine. 36 (7), 1302-1303.

[13] Fujita N, Tambo M, Okegawa T, Higashihara E, Nutahara K. (2017). Distinguishing testicular torsion from torsion of the appendix testis by clinical features and sign in patients with acute scrotum. Research representave Urology 9, 164-174.

[14] Burgher SW (1998). Acute scrotal pain. Emergency Medical Clinics of North America 4, 781-809.

[15] Kadish HA, Bolte RG (1998). A retrospective review of pediatric patients with epididymitis, testicular torsion, and torsion of testicular appendages. Pediatrics 102, 73-76. 
[16] Chia-Chu Liu, Shu-Pin Huang, Yii-Her Chou, Ching-Chia $\mathrm{Li}$, Ming-Tsang $\mathrm{Wu}$, Chun-Hsiung Huang, Wen-Jeng Wu (2007). Clinical presentation of acute scrotum in young males. Kaohsiung Journal of Medical Science 23 (6), 281-285.

[17] Lyronis ID, Ploumis N, Vlahakis I, Charissis G. (2009). Acute scrotum -etiology, clinical presentation and seasonal variation. Indian Journal of Pediatrics. 76 (4), 407-410.

[18] Sellars M E and Sidhu P S (2003). Ultrasound appearances of the testicular appendages: pictorial review. European Radiology 13, 127-135.

[19] Hesser U, Rosenborg M, Gierup J (1993). Grey scale sonography in torsion of the testicular appendages. Pediatric Radiology 23, 529-532.

[20] Strauss S, Faingold R, Manor H (1997). Torsion of the testicular appendages: sonographic appearance. Journal of Ultrasound and Medicine 16, 189-192.

[21] Cohen H L, Shapiro M A, Haller J O (1992). Torsion of the testicular appendage: sonographic diagnosis. Journal of Ultrasound and Medicine 11, 81-83.
[22] Johnson K A and Dewbury K C (1996). Ultrasound imaging of the appendix testis and appendix epididymis. Clinical Radiology 51, 335-337.

[23] Rolnick D, Kawanoue S, Szanto P (1968). Anatomical incidence of testicular appendages. Journal of Urology 100, 755-756.

[24] Dogra V S, Gottlieb R H, Oka M (2003). Sonography of the scrotum. Radiology 227, 18-36.

[25] Ivens U (1972). Morphology and function of the appendix testis. Andrologie 4, 245-258.

[26] Jacob M, Barteczko K (2005). Contribution to the origin and development of the appendices of the testis and epididymis in human. Anatomical Embryology 209, 287-302.

[27] Yang D M, Lim J W, Kim J E (2005). Torsed appendix testis. Journal of Ultrasound and Medicine 24, 87-91.

[28] Rakha E, Puls F, Saidul I and Furness P (2006). Torsion of the testicular appendix: importance of associated acute inflammation. Journal of Clinical Pathology 59, 831-834. 